\title{
Perancangan Animasi 3 Dimensi Alur Pengurusan Administrasi Pasien Umum Dan Jaminan Dibagian Rehabilitasi Medik RSUP Prof. DR. R.D Kandou Manado
}

\author{
Ryan Pangemanan, Rizal Sengkey, Oktavian A. Lantang \\ Teknik Informatika Universitas Sam Ratulangi Manado, Indonesia. \\ pangemanan28@gmail.com, rizalsengkey@gmail.com, oktavian@unsrat.ac.id
}

\begin{abstract}
Abstrak-Laporan tugas akhir yang berjudul Perancangan Animasi 3D Alur Pelayanan Administrasi Pasien Umum Dan Jaminan Di Bagian Rehabilitasi Medik RSUP Prof. Dr. R.D Kandou Manado ini bertujuan untuk mengetahui : langkah atau alur proses pengurusan administrasi pasien yang akan berobat, di jelaskan dengan mudah tahapan-tahapan yang harus di lalui sampai pasien mendapatkan perawatan oleh dokter sesuai dengan penyakit yang di derita oleh pasien. Dalam pembuatan animasi 3 dimensi ini, dimulai dengan menentukan ide dan tema dengan cara melakukan wawancara dan pengumpulan data di lokasi penelitian. Selanjutnya dilakukan proses modeling, texturing, rigging, animating dan rendering dengan meggunakan aplikasi Blender dan Makehuman. Tahapan berikut yaitu menyatukan potongan-potongan Video Animasi yang telah di rendering dan menambahkan teks-teks bantuan dengan menggunakan aplikasi adobe premier pro cs5.
\end{abstract}

Kata Kunci : Blender, Rehabilitasi Medik, Jaminan Kesehatan, Animasi 3D

\section{PENDAHULUAN}

Dengan berkembangnya zaman, saat ini animasi tidak hanya digunakan untuk hiburan semata. animasi bisa digunakan sebagai alat untuk membantu manusia dalam kehidupan seharihari. Animasi memiliki kemampuan untuk memaparkan sesuatu yang rumit hanya melalui gambar dan kata-kata saja, dengan cara visualisasi sebuah maksud dapat tergambarkan. Dengan adanya media informasi menggunakan animasi maka proses penyampaian suatu informasi akan lebih mudah untuk di pahami dan dimengerti dibandingkan menggunakan lisan maupun tulisan.

Animasi di dalam sebuah aplikasi multimedia menjanjikan suatu tampilan visual yang lebih dinamis, dapat menampilkan sesuatu yang mustahil atau kompleks dalam kehidupan yang sebenarnya dan dapat direalisasikan di dalam aplikasi tersebut. Sebagai contoh apabila aplikasi multimedia tersebut ingin menjelaskan proses suatu peristiwa alam seperti hujan, mungkin sulit untuk diperagakan atau di buktikan secara nyata, maka dengan adanya animasi multimedia maka hal itu bisa digambarkan, dipaparkan dalam bentuk gambar bergerak yang seolah-olah hidup.

Dalam kehidupan manusia sehari-hari masalah kesehatan merupakan hal yang utama, banyak jenis masalah kesehatan dari yang tergolong ringan maupun masalah kesehatan yang berat. Saat ini juga banyak metode pengobatan mulai dari pengobatan secara tradisional maupun yang modern. Menurut WHO (World Health Organization) badan resmi yang menaungi kesehatan di dunia, kesehatan adalah keseimbangan yang sempurna, baik fisik, mental, dan social, tidak hanya bebas dari penyakit dan kelemahan.

Dalam bidang kesehatan animasi juga dapat membantu manusia, misalnya alur pengurusan administrasi pasien Umum dan Jaminan di bagian Rehabilitasi Medik RSUP Prof. Dr. R.D Kandou Manado. Dengan banyaknya jumlah pasien baru yang bertambah tiap bulan, kebutuhan pasien untuk menerima informasi tentang alur pengurusan administrasi sangat di butuhkan. Untuk mendapatkan informasi saat ini pasien mendapatkannya dengan cara bertanya secara langsung kepada perawat atau dokter.

\section{DASAR TEORI}

\section{A. Definisi Perancangan}

Menurut Jogiyanto H.M (2001:196), Perancangan Sistem yaitu: "Perancangan Sistem dapat didefenisikan sebagai penggambaran, perencanaan, dan pembuatan sketsa atau pengaturan dari beberapa elemen yang terpisah kedalam satu kesatuan yang utuh dan berfungsi". Pengertian perancangan sistem yang lain menurut Jogiyanto H.M (2001:196), yaitu : "Perancangan sistem menentukan bagaimana suatu sistem akan menyelesaikan apa yang mesti diselesaikan. Tahap ini menyangkut mengkonfigurasikan dari komponen-komponen perangkat lunak dan perangkat keras dari suatu sistem sehingga setelah instalasi dari sistem akan benar-benar memuaskan rancangan bangun yang telah ditetapkan pada akhir tahap analisa sistem".

\section{B. Animasi}

Animasi menurut Agus Suheri (2006: 2) "Merupakan kumpulan gambar yang diolah sedemikian rupa sehingga menghasilkan gerakan". Animasi mewujudkan ilusi (illusion) bagi pergerakkan dengan memaparkan atau menampilkan satu urutan gambar yang berubah sedikit demi sedikit (progressively) pada kecepatan yang tinggi. Animasi digunakan 
untuk memberi gambaran pergerakan bagi sesuatu objek. Animasi membolehkan sesuatu objek yang tetap atau statik dapat bergerak dan kelihatan seolah-olah hidup. Animasi multimedia merupakan proses pembentukan gerak dari berbagai media atau objek yang divariasikan dengan efek-efek dan filter, gerakan transisi, suara-suara yang selaras dengan gerakan animasi tersebut.

\section{3 Dimensi}

3D adalah dimensi yang memiliki ruang. Jika kita merujuk kepada "objek 3D", artinya objek tersebut memiliki ruang atau volume. Objek 3D juga memiliki lokasi pada koordinat X, Y dan Z. Jika pada bidang 2 dimensi anda hanya dapat menggerakkan objek tersebut ke samping kanan dan kiri (X), atas dan bawah (Y), dalam ruang $3 \mathrm{D}$ selain dapat digerakkan ke samping kanan dan kiri objek juga dapat digerakkan ke depan dan ke belakang (Z).

\section{Pasien Umum dan Jaminan}

Pasien umum adalah pasien yang akan berobat di bagian rehabilitasi medik tanpa jaminan atau pasien yang mempunyai tagihan di luar jaminan. Sedangkan pasien jaminan adalah pasien yang segala kebutuhan administrasi atau pembayaran di tanggung oleh perusahaan, asurasi dan BPJS.

\section{E. Rehabilitasi Medik}

Rehabilitasi medik adalah bagian dari rumah sakit yang melayani kesehatan terhadap gangguan fisik dan fungsional yang diakibatkan oleh keadaan atau kondisi sakit, penyakit atau cedera melalui panduan intervensi medik, keterapian fisik dan atau rehabilitatif untuk mencapai kemampuan fungsi yang optimal.

\section{F. RSUP Prof DR. R.D Kandau Manado}

RSUP Prof.Dr. R.D Kandou Manado adalah rumah sakit negeri kelas B. Rumah sakit ini mampu memberikan pengurusan kedokteran spesialis dan subspesialis terbatas. Rumah sakit ini juga menampung pengurusan rujukan dari rumah sakit kabupaten. Tempat ini tersedia 745 tempat tidur inap, lebih banyak dibanding setiap rumah sakit di Sulawesi Utara yang tersedia rata-rata 65 tempat tidur inap. Dengan 206 dokter, rumah sakit ini tersedia lebih banyak dibanding rata-rata rumah sakit di Sulawesi Utara.

\section{Metodologi Penelitian}

\section{A. Metode Pengumpulan Data}

Metode penelitian yang diterapkan dalam mendapatkan data dan informasi yang mendukung dalam penelitian ini adalah sebagai berikut:

$$
\text { - Studi Lapangan }
$$

Dalam melakukan penelitian di lapangan akan didapatkan data yang terdapat dalam dokumendokumen instansi terkait, serta langsung mengamati, mengevaluasi, sistem pengurusan administrasi pasien umum dan jaminan. Pada penelitian ini juga akan dilakukan wawancara dengan narasumber atau pihakpihak yang berhubungan dengan masalah-masalah tersebut.

a. Teknik wawancara, yaitu dengan langsung bertatap muka dengan pihak-pihak terkait yaitu Dinas Perhubungan dan sopir angkutan umum.

b. Teknik observasi dan dokumentasi, Proses pendokumentasian saat penulis melakukan observasi di Bagian Rehabilitasi Medik RS. Prof. DR. R.D Kandou Manado berupa data dan foto.

\section{B. Metode Perancangan}

Metode Perancangan merupakan tiap-tiap prosedur, teknik yang di gunakan oleh penulis dalam proses perancangan secara keseluruhan, Pada metode atau langkah-langkah dalam perancangan terdapat tiga tahapan pembuatan yaitu : Tahap Pra-Produksi, Tahap Produksi Dan Tahap Pasca. Berikut adalah Langkah-langkah Perancangan Animasi:

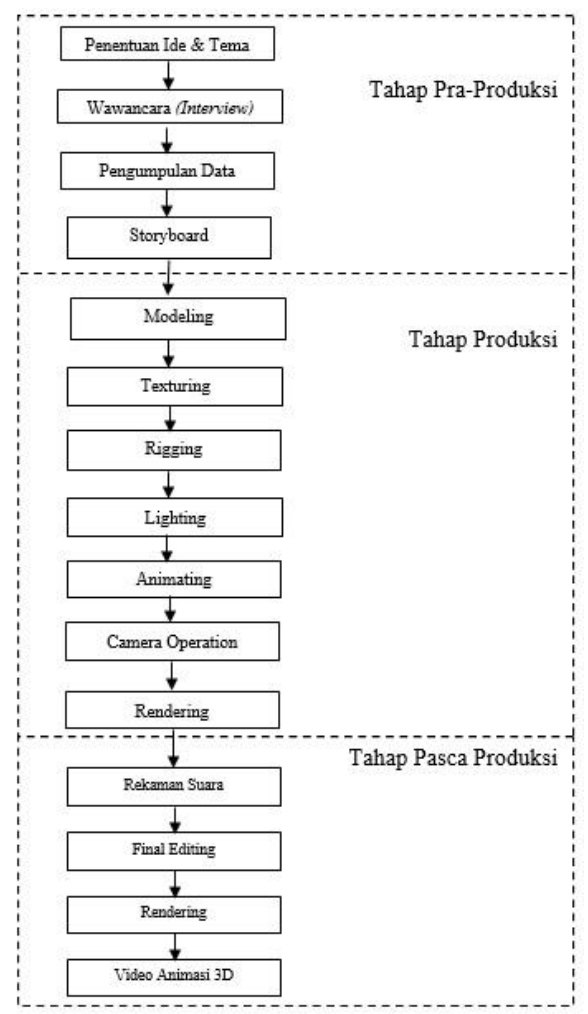

Gambar 3.1 Langkah-Langkah Perancangan Animasi

Selanjutnya adalah gambar diagram alur pengurusan pasien umum dan jaminan dibagian Rehabilitasi medik RSUP Prof DR. R.D Kandou Manado yang saat ini digunakan. 


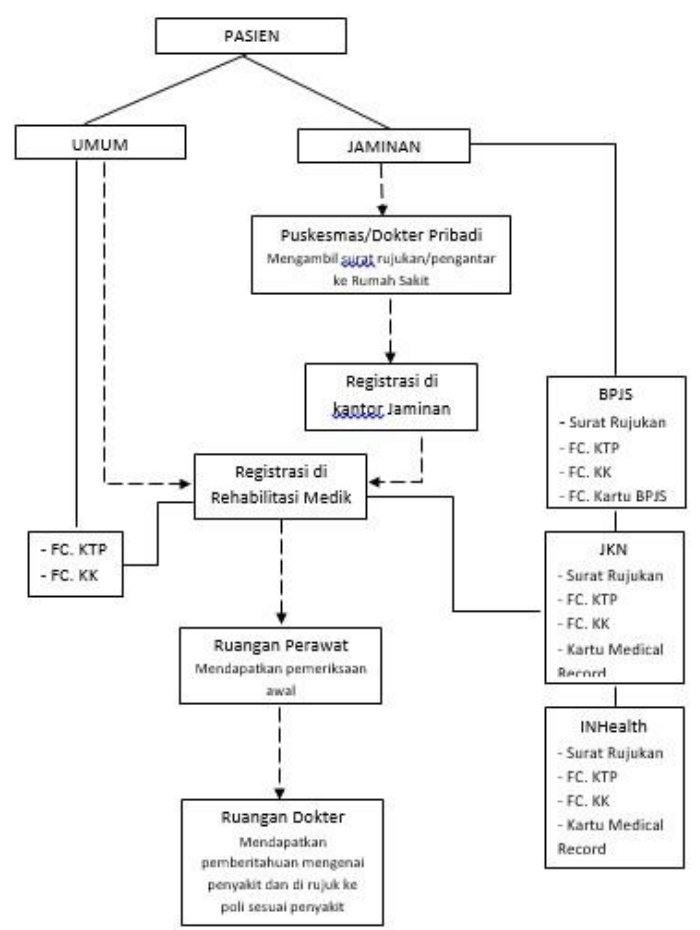

Gambar 3.2 Alur Mekanisme Pengurusan Administrasi Pasien Umum dan Jaminan

\section{IV . Hasil dan Pembahasan}

\section{A. Tahap Produksi}

Setelah membahas tentang tahap pra produksi yaitu tahap pembahasan tentang metode yang digunakan serta tahap pengumpulan data serta observasi lapangan, maka pada bagian ini akan dibahas bagaimana animasi itu di buat sesuai dengan storyboard yang telah ditentukan.

\subsection{Modeling}

Pada perancangan dan pembuatan video animasi 3 dimensi pengurusan administrasi pasien umum dan jaminan ini memakai objek Cube, plane dan cylinder. Kemudian proses pembentukan model objek dilakukan pada Edit Mode dengan bantuan fungsi ekstrude, skala, dan grab hingga terbentulah model objek sesuai keinginan penulis.

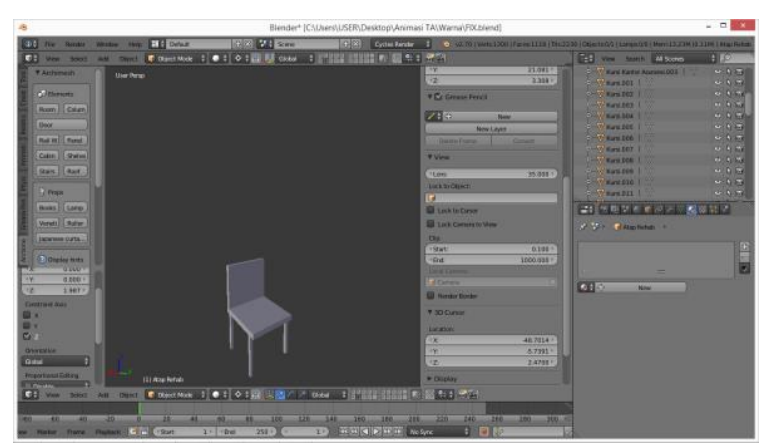

Gambar 4.1 Tahap Modeling

\subsection{Teksturing}

Pada proses teksturing ini penulis menambahkan tekstur atau warna yang sesuai dengan objek aslinya sehingga terlihat lebih natural dan alami. Proses teksturing dalam aplikasi blender dapat dibuat dengan menggunakan tools material yang ada pada kolom properties pada aplikasi blender, Teksturing objek yang dibuat oleh penulis.

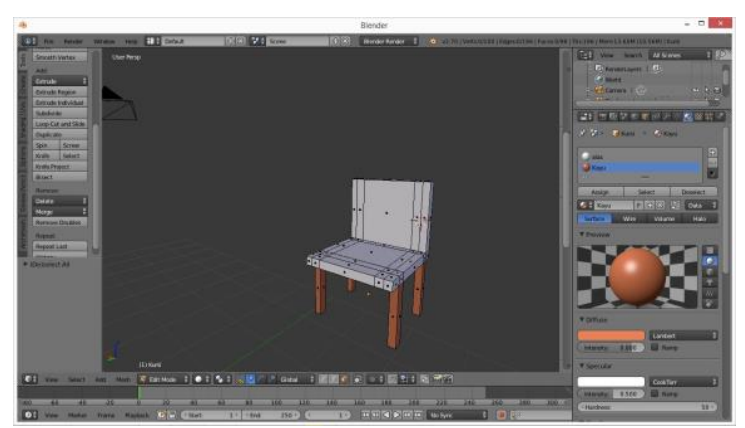

Gambar 4.2 Tahap Teksturing

\subsection{Rigging}

Pada tahap riging ini penulis melakukan proses pemasangan tulang pada objek atau model manusia di aplikasi Blender agar dapat di animasikan atau digerakan. Pemasangan tulang dilakukan pada saat objek manusia selesai dibuat.

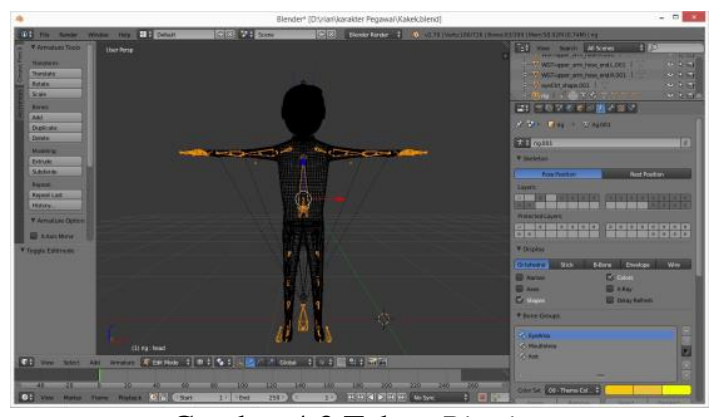

Gambar 4.3 Tahap Rigging

\subsection{Lighting}

Pada tahap Lighting penulis melakukan pemberian cahaya pada model sehingga diperoleh kesan visual yang realistis. lamp atau lampu terdapat beberapa macam di antaranya point, sun, spot, hemi, area namun yang penulis gunakan ada dua macam yaitu Point dan Sun.

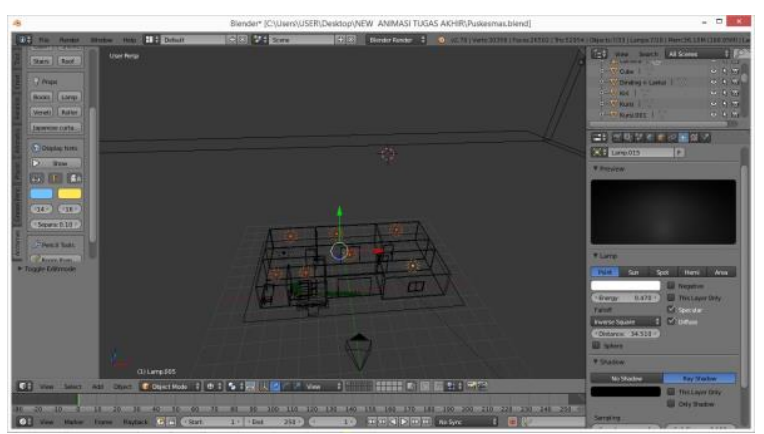

Gambar 4.4 Tahap Lighting 


\subsection{Animating}

Tahap animating merupakan tahap dimana penulis melakukan pengaturan pergerakan objek animasi dengan memberikan gerakan pada objek maupun pada kemera sesuai storyboard. Pembuatan animasi sendiri dilakukan secara manual agar dapat lebih mudah menyesuaikan karakter dan disesuaikan dengan storyboard yang telah dibuat oleh penulis.

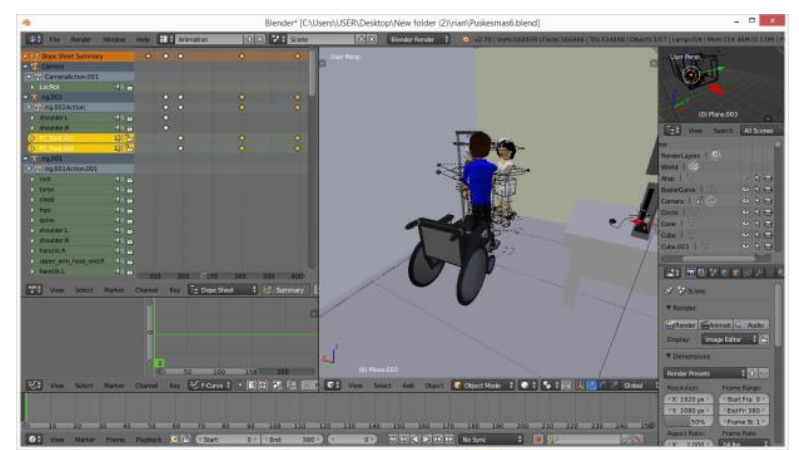

Gambar 4.5 Tahap Animating

\subsection{Camera Operation}

Pada tahap camera operation ini penulis melakukan pengoprasian kamera masih di dalam tools animattion agar dapat melihat pergerakan objek manusia dan merekam objek tersebut yang telah di animasikan oleh penulis.

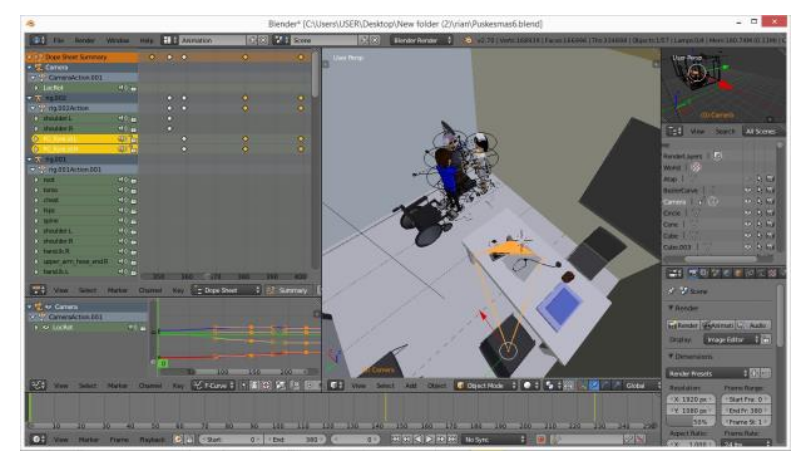

Gambar 4.6 Tahap Camera Operation

\subsection{Rendering}

Pada tahap rendering ini dilakukan untuk membuat animasi kedalam bentuk video 3 dimensi. Proses rendering dilakukan pada setiap adegan satu demi satu hingga menjadi beberapa video animasi 3 dimensi untuk pengurusan administrasi.

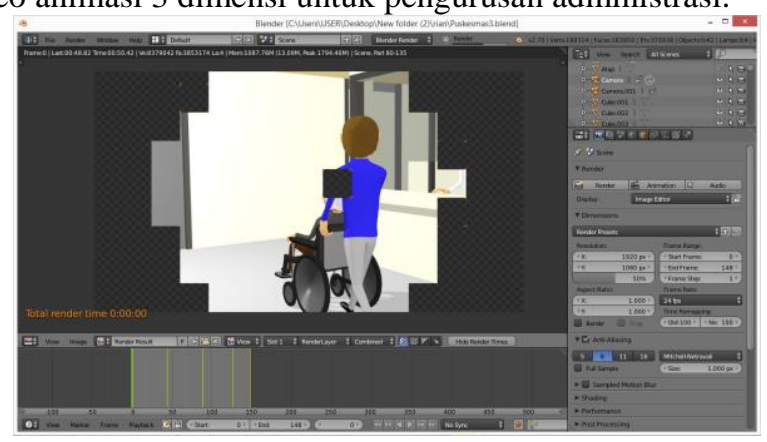

Gambar 4.7 Tahap Rendering
B. Tahap Pasca Produksi

\subsection{Rekam Suara}

Proses perekaman suara dilakukan dengan aplikasi windows yaitu Sound Recorder dengan format file perekaman menjadi format wav.

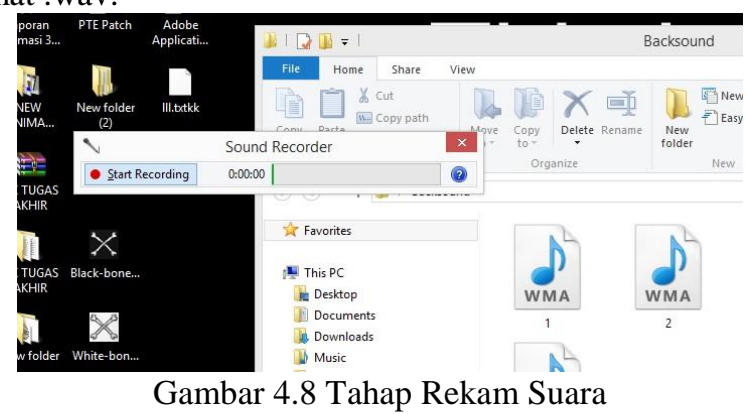

\subsection{Final Editing}

Final Editing merupakan bagian terakhir dari proses pembuatan video animasi 3 dimensi untuk pengurusan administrasi. Dimana semua file video 3 dimensi hasil render pada aplikasi Blender dan file audio yang dibuat pada aplikasi Adobe Sound Recorder diimport kedalam aplikasi Adobe Premiere Pro.

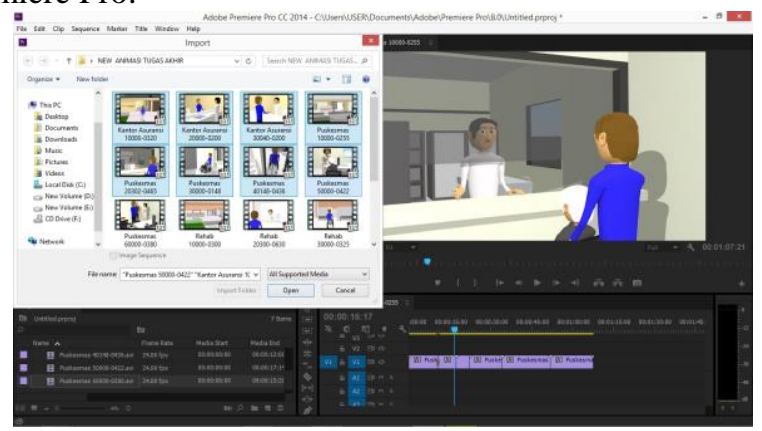

Gambar 4.9 Tahap Final Editing

\subsection{Final Rendering}

Final Rendering merupakan tahap akhir dari pembuatan video animasi 3 dimensi pada aplikasi Adobe Premiere Pro CS5 dengan output animasi 3 dimensi. Pada gambar 4.10 merupakan proses untuk mengexport file video animasi 3 dimensi dengan 2 file video yang telah di pisahkan menurut jenis pengurusan, dan masing-masing file video berdurasi 03 menit 12 detik untuk video pasien jaminan, dan 02 menit 21 detik untuk video pasien umum.

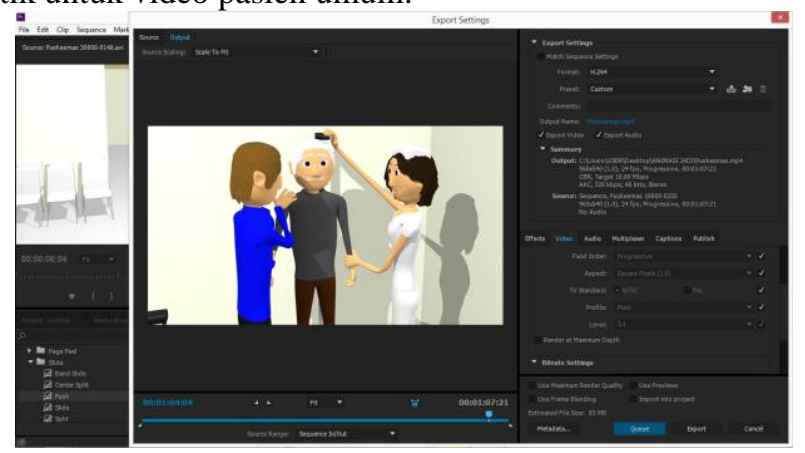

Gambar 4.10 Tahap Final Rendering 


\subsection{Hasil Video}

Gambar 4.11 adalah hasil dari video animasi 3 dimensi untuk alur pengurusan untuk pasien jaminan dengan format file avi beresolusi $950 \mathrm{X} 540$ pixel berdurasi 3 menit dan 12 detik dan ukuran file $162 \mathrm{MB}$.

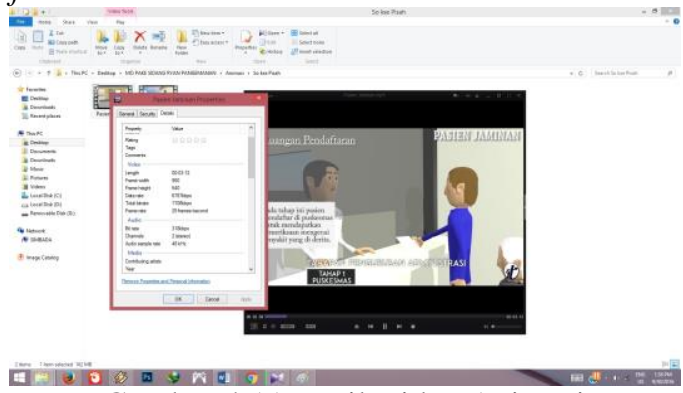

Gambar 4.11 Hasil Video Animasi

\section{IV.PENUTUP}

\section{A. Kesimpulan}

Setelah menyelesaikan proses pembuatan animasi 3 dimensi untuk mekanisme alur pengurusan administrasi ini penulis dapat mengambil beberapa kesimpulan, sebagai berikut :

1. Menghasilkan video animasi 3 dimensi untuk mekanisme alur pengurusan pasien umum dan jaminan yang akan berobat di bagian Rehabilitasi Medik RS. Prof. Dr. R.D Kandou Manado.

2. Video animasi 3 dimensi ini memberikan kesempatan kepada penulis untuk mengembangkan kemampuan dalam hal ini membuat animasi.

\section{B. Saran}

1. Video animasi 3 dimensi sebaiknya digunakan dengan ditampilkan melalui layar dan di letakan di ruang tunggu Di bagian Rehabilitasi Medik.

2. Dalam pembuatan animasi 3 dimensi dibutuhkan perangkat komputer yang memadai khususnya dalam melakukan animation atau menggerakan objek dan rendering contohnya processor Intel CoreTM i5$421 \mathrm{OU}$ CPU up to $2.70 \mathrm{GHz}$, Memory 4 GB DDR3, HDD 1 TB Seagate dan VGA Nvidia GeForce 840M.

\section{DAFTAR PUSTAKA}

[1] Aplikasi Blender. 2015. Tersedia di : https://www.blender.org/

[2] H.M, Jogiyanto. Definisi Perancangan. Yogyakarta : Penerbit Andi, 2001.

[3] Suheri, Agus. Animasi Multimedia Pembelajaran, Jurnal Media Teknologi, Vol 2. No 1. Cianjur : Universitas Suryakencana, 2006.

[4] Utami, Dini. Animasi Dalam Pembelajaran. Yogyakarta : UNY, 2007.
[5] Wahyu,S Novian. Animasi Pembelajaran Untuk Pendidikan Bogor : Bhineka,_(2005).

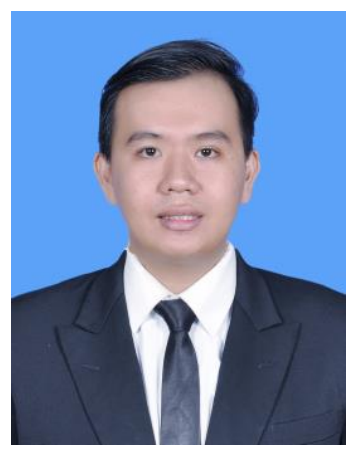

Sekilas dari penulis dengan nama lengkap Ryan Pangemanan, lahir di Manado, Provinsi Sulawesi Utara, anak ke 2 dari 2 bersaudara. Dengan Pendidikan Sekolah Dasar Inpres Kembes. Kemudian melanjutkan ke Sekolah Menengah Pertama Negeri 8 Manado. Kemudian melanjutkan ke Sekolah Menengah Kejuruan (SMK) Negeri 2 Manado. Setelah lulus tahun 2010 melanjutkan ke Perguruan Tinggi di Universitas Sam Ratulangi Manado dengan mengambil Jurusan Teknik Informatika. Pada tanggal 26 September 2016 Penulis Resmi lulus di Teknik Informatika Universitas Sam Ratulangi Manado dan menyandang gelar Sarjana Komputer. 